\title{
Quantitation of diarrhetic shellfish poisoning toxins in Chilean Mussel using pyrenyldiazomethane as fluorescent labeling reagent
}

\author{
CARLOS GARCÍA ${ }^{1}$, PAULO PEREIRA ${ }^{2}$, LUIS VALLE ${ }^{3}$ and NÉSTOR LAGOS ${ }^{1}$
}

${ }^{1}$ Lab. Bioquímica de Membrana, Dept. de Fisiología y Biofísica, Facultad de Medicina, Universidad de Chile, Santiago, Chile.

${ }^{2}$ Laboratorio de Microbiología Experimental, Instituto Nacional de Saúde, 1649-016, Lisbon, Portugal.

${ }^{3}$ CEPEDEQ, Facultad de Ciencias Químicas y Farmacéuticas, Universidad de Chile.

\begin{abstract}
Diarrhetic shellfish poisoning (DSP) is a gastrointestinal disease caused by lipid soluble polyether toxins produced by dinoflagellates and accumulated in shellfish. Diarrhetic shellfish poisoning is a worldwide threat to public health and the shellfish industry. To date, only four lipid soluble polyethers have been known as diarrhetic shellfish toxins. Among them, Okadaic acid (OA), Dinophysistoxin 1 (DTX-1, 35-methyl OA), Dinophysistoxin 2 (DTX-2, OA isomers) and Dinophysistoxin 3 (DTX-3, 7-O-acyl-35-methyl OA), all of which have free carboxilic groups. To perform quantitative analysis of DSP toxins in shellfish samples is a requirement, because DSP toxins are endemic in the Chilean mollusks of the southern regions, and although human symptoms of DSP appear relatively mild in comparison with the Paralytic Shellfish Poisoning (PSP), the necessity of monitoring the chronic effects of continued uptake of low doses of DSP toxins more closely is imperative, since DSP toxins have been described as potent tumor promoters.

This paper shows the synthesis pathway of a chromophore, 1-pyrenyldiazomethane (PDAM), a fluorescent labeling reagent for determination of carboxilic acids, using High Performance Liquid Chromatography with fluorescence on-line detection. This procedure was developed in order to have a quantitative method for DSP toxins analysis that would be useful for health public services and private shellfish industries. The features of this labeling reagent are compared against ADAM and used for quantitative analysis of DSP toxins in Chilean mussels and cultured dinoflagellates samples.
\end{abstract}

Key terms: DSP toxins, Okadaic acid, Dinophysistoxin-1 (DTX-1), Pyrenyldiazomethane (PDAM), Patagonian fjords, Chile.

\section{INTRODUCTION}

Under certain environmental conditions, marine and freshwater phytoplankton may proliferate, causing massive fish kills, contaminated seafood and altered ecosystems in ways that humans perceive as harmful (White 1988; Anderson 1989; Smayda 1992; Lagos 1998). These events are generically referred to as harmful algal bloom (HAB) and popularly known as Red Tides. HAB has been shown to produce negative impacts worldwide, with economics losses and human poisoning (Anderson 1989; Hallegraeff 1993; Proenca et al., 1997; Lagos 1998). Although HABs occurred long before human activities began to transform coastal ecosystems, a survey of affected regions, economic losses, and human poisonings throughout the world clearly demonstrates that there has been a dramatic increase in the negative impact of HABs over the last few decades (Hallegraeff 1993; Lagos 1998).

Some organisms that are responsible for HABs are well known because they are toxins producers. To date, six important human illnesses associated with microalgae toxins have been described (Hallegraeff 1993; Yasumoto and Murata

Corresponding Author: Néstor Lagos, Ph.D., Lab. Bioquímica de Membrana, Universidad de Chile, Casilla 70005, Correo 7, Santiago, Chile. Telephone: (56-2) 678-6309 - Fax: (56-2) 777-6916. E-mail: nlagos@ machi.med.uchile.cl 
1993; Yasumoto et al., 1995; Falconer 1996, Lago 1998). Of these, two are endemically present in the southern part of Chile (Patagonian fjords): Paralytic Shellfish Poisoning (PSP) and Diarrhetic Shellfish Poisoning (DSP), both very well documented (Lembeye et al., 1975; Muñoz et al., 1992; Zhao et al., 1993; Uribe 1993; Lagos et al., 1996; Compagnon et al., 1998; Rivas et al., 2000; Uribe et al., 2001; Lagos 2002).

Diarrhetic Shellfish Poisoning (DSP) is a worldwide distributed gastrointestinal illness which shows a rapid-onset intoxication involving consumption of shellfish containing toxins that are produced by dinoflagellates of the genera Dinophysis spp. and Prorocentrum spp (Yasumoto et al., 1978; Yasumoto and Murata 1993).

Outbreaks associated with DSP have occurred in the Patagonian fjords since 1970 (Muñoz et al., 1992; Uribe et al., 2001). Historically, the northern part of the Patagonian fjords (above $46^{\circ} 00^{\prime} \mathrm{SL}$ ) have been affected with DSP, including localities

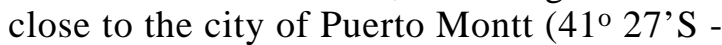
$\left.72^{\circ} 57^{\prime} \mathrm{W}\right)$ and some areas in the Aysén Region (ca. $44^{\circ}-48^{\circ} \mathrm{SL}$ ). In both localitions, some of these outbreaks have been associated with the presence of Dinophysis acuta Ehrenberg, (Zhao et al., 1993; Lembeye et al., 1993). Recently, Uribe et al. 2001, have addressed the presence of DSP toxins in a Chilean filterfeeding bivalve mollusc (Mytilus chilensis Hupe) collected in a southern Magellanic fjord during a bloom of Dinophysis acuminata Clarapéde \& Lachmann. This is the first report and quantitative analysis of DSP toxins in this remote southern area in the Magellan Region. Currently, the three austral Regions of Chile show the endemic presence of DSP toxins.

Until now, attempts for evaluating DSP toxins in Chile have been limited to the use of mouse bioassay. All performed by the Regional Monitoring Program for preventing human poisonings. However, positive results for DSP toxins have been inconclusive for four major reasons: they have not been associated with the presence of toxic or potentially toxic phytoplankter species; death in most of the mice was produced without any evidence of gastrointestinal symptoms; the coexistence of endemic PSP toxins in the same mollusc at low concentrations produces death in mice with similar symptoms and over periods of 6 or more hours, similar to DSP; false positives in these bioassays; and finally, because there is no sensitive quantitative method available to measure these toxins.

In Chile it is very important to perform quantitative analysis of DSP toxins in shellfish samples. First, because DSP toxins are endemic in the Chilean molluscs of southern regions; second, the mouse bioassay performed in Chile is merely qualitative, so the level of toxins is never known; third, although human symptoms of DSP appears relatively mild in comparison with the Paralytic Shellfish Poisoning (PSP), it is imperative to monitor the chronic effects of continued uptake of low doses of DSP toxins, as these DSP toxins have been described as potent tumor promoters (Suganuma et al., 1988).

The present paper shows the pathway to developing the synthesis of a fluorescent chromophore, 1-pyrenyldiazomethane (PDAM), a fluorescent labeling reagent for the determination of carboxilic acids using High Performance Liquid Chromatography (HPLC). PDAM has previously been used as a derivatization reagent for fatty acids and protaglandins (Nimura et al., 1988). This procedure was developed in order to have a quantitative method of DSP toxin analysis that would be useful to the health public services as well as the private shellfish industry and to overcome the uneasy access, high cost, chemical instability and problems of shipping and handling 9-anthryldiazomethane (ADAM), the most commonly used fluorescent chromophore for quantitative analysis of DSP toxins (Lee et al., 1987). The synthesis of this compound was achieved starting from methylpyrene. The features of this labeling reagent are compared against ADAM and then used to detect and make quantitative analysis of DSP toxins in Chilean mussel and cultured dinoflagellate samples. 
MATERIALS AND METHODS

\section{Reagents}

The Okadaic acid (OA) and Dinophysistoxin-1 (DTX-1) standard toxins were obtained from SIGMA (Sigma Chemical Co, St, Louis, MO, USA), 9antryldiazomethane (ADAM) was purchased from Funakoshi Pharmacy (Tokyo, Japan), 1-pyrenyldiazomethane (PDAM) was synthesized in our laboratory, and Deoxycholic acid (DOCA) was purchased from SIGMA (Sigma Chemical Co, St, Louis, MO, USA). HPLC grade solvents (acetonitrile, acetone, methanol, nhexane, chloroform, dichloromethane) were purchased from Merck (Merck, Darmstadt, Germany). The SEP-PAK Cartridges for solid phase extraction of Silica and $\mathrm{C}_{18}$, were purchased from Waters Corporation (Division of MILLIPORE, Milford, MA. USA).

\section{Mussel Extracts}

The mussel extracts were obtained from samples collected in April 2000 from the XI Region. The digestive glands of Mytilus chilensis Hupe were removed, then two grams of this tissue were homogenized and extracted twice with $3 \mathrm{ml}$ of chilled $80 \%$ methanol, under mechanical stirring using a tissue tearor biohomogenizer (model $\mathrm{M}$ 133/2280, Biospec Products, Inc., Bartlesville, OK, USA). The metanolic phase was then centrifugated at $1500 \mathrm{x} \mathrm{g}$ for $5 \mathrm{~min}$. Then $2.5 \mathrm{ml}$ of the supernatant was diluted with water to a final $26.66 \%$ methanol. From this dilution, $5 \mathrm{ml}$ were then transferred to a $250 \mathrm{mg} \mathrm{C}_{18}$ SEP PAK cartridge. The system was washed with 5 $\mathrm{ml}$ of $50 \%$ methanol (this volume was discarded, to remove lipid components), then to elute the DSP toxins, $5 \mathrm{ml}$ of pure methanol was added. This eluate was evaporated to dryness under reduced pressure in a Speed Vac Plus (Savant, SC 210A, Farmingdale, NY, USA). These clean and dry extracts were used for derivatization with ADAM or PDAM.

\section{Dinoflagellates extracts}

Cell pellets ( $P$. lima) that were treated twice by freeze-thawing procedures, were suspended in $1 \mathrm{ml}$ of aqueous methanol $80 \%$ and sonicated for $1 \mathrm{~min}$ at room temperature. After centrifugation the supernatant was decanted and the pellet was re-extracted twice with $1 \mathrm{ml}$ aqueous methanol $80 \%$. The supernatants were combined into a $5 \mathrm{ml}$ glass vial and evaporated in Speed Vac SC 210A with refrigerated vapor trap RVT400 (SAVANT). The residue was dissolved in 2 $\mathrm{ml}$ of $80 \%$ methanol and extracted with 2 $\mathrm{ml}$ of hexane. The methanolic layer was dried and preserved frozen until preparation of PDAM derivatives.

Synthesis and reactions to produce 1-pyrenyldiazomethane (PDAM)

The PDAM was synthesized via three major steps. First the synthesis of pyrenylchloromethane, then the synthesis of 1-pyrenilaminomethane was achieved, and finally a diazotisation reaction of 1 pirenylaminomethane was done in order to produce 1-pyrenyldiazomethane.

\section{A. Synthesis of pyrenylchloromethane.}

The following reagents were mixed in a three-mouth flask: 7.25 grams of pyrene, 2.5 grams of paraformaldehyde, $6.25 \mathrm{ml}$ of acetic acid, $3.38 \mathrm{ml}$ of concentrated phosphoric acid, and $7.5 \mathrm{ml}$ of concentrated hydrochloric acid. This mixture was warmed for 6 hours with constant agitation controlling the temperature in a range of $95^{\circ} \mathrm{C}$ to $100{ }^{\circ} \mathrm{C}$. The reaction was stopped by adding $50 \mathrm{ml}$ of ice water. The cool mixture was set aside in a decantation funnel. Once decanted, the dense oil of the bottom was washed four times with water by means of the decantation funnel. The thick oil that remains was transparent with a dark yellow color. After distillation and crystallization, the transparent yellow compound proved to be at least $90 \%$ pyrenylchloromethane. 


\section{B. Synthesis of 1-pyrenylaminomethane}

In a three-mouth flask, 5 grams of pyrenylchloromethane were mixed with $12.5 \mathrm{ml}$ of $40 \%$ ammonium sulfite in water and $3 \mathrm{ml}$ of $20 \%$ ammonia. The mixture was warmed to $150{ }^{\circ} \mathrm{C}$ for 6 hours, the product was cooled to room temperature and then filtered in Whatman paper \# 1 . The filtrate was washed twice with diluted alkali $(60 \% \mathrm{NaOH})$ to separate the residues of the reaction. In each wash, the phases were separated in a decantation funnel. The final organic phase was crystallized twice.

\section{C.Preparation of 1-pyrenyldiazomethane (PDAM)}

In a $100 \mathrm{ml}$ beaker, $5.5 \mathrm{ml}$ of concentrated sulfuric acid was cautiously poured into 7.5 $\mathrm{ml}$ of the cooled stirring water. Then, 2 grams of the above crystallized 1pyrenylaminomethane were incorporated. Then, 10 to $15 \mathrm{gr}$. of finely crushed ice were added to the mixture and stirred until when the pyrenylaminomethane was transformed into the sulphate form. Here, a homogeneous red paste was obtained. The product was cooled to $0-4{ }^{\circ} \mathrm{C}$ by immersing the beaker in a freezing mixture of water and ice. At 0-4 ${ }^{\circ} \mathrm{C}$ and with mechanical stirring, a cold solution of 1.8 grams of sodium nitrite in 5 $\mathrm{ml}$ of water was added over a period of 10 minutes until a permanent brick red color was obtained. The temperature was then maintained in a range of $5-7{ }^{\circ} \mathrm{C}$ during the diazotisation reaction. The stirring was continued for 5 minutes and the product was allowed to stand for 5 minutes. Some pyrenyldiazomethane sulphate solids were decanted out. The supernatant was separated immediately from the decanted solid by filtration with a G-3 glass filter. This product was evaporated until dry under reduced pressure in Speed Vac SC 210A with a refrigerated vapor trap RVT400 (SAVANT) to give red crystalline PDAM. The crystals were weighted and kept in a freezer at $-20^{\circ} \mathrm{C}$ until used. Figure 1 shows the reaction sequence that describes the syntheses and reactions to produce the fluorescent labeling reagent 1-pyrenyldiazomethane (PDAM).

$$
\mathrm{CH}_{2} \mathrm{O}+\mathrm{H}^{+} \rightleftharpoons{ }_{\mathrm{CH}}^{+}
$$
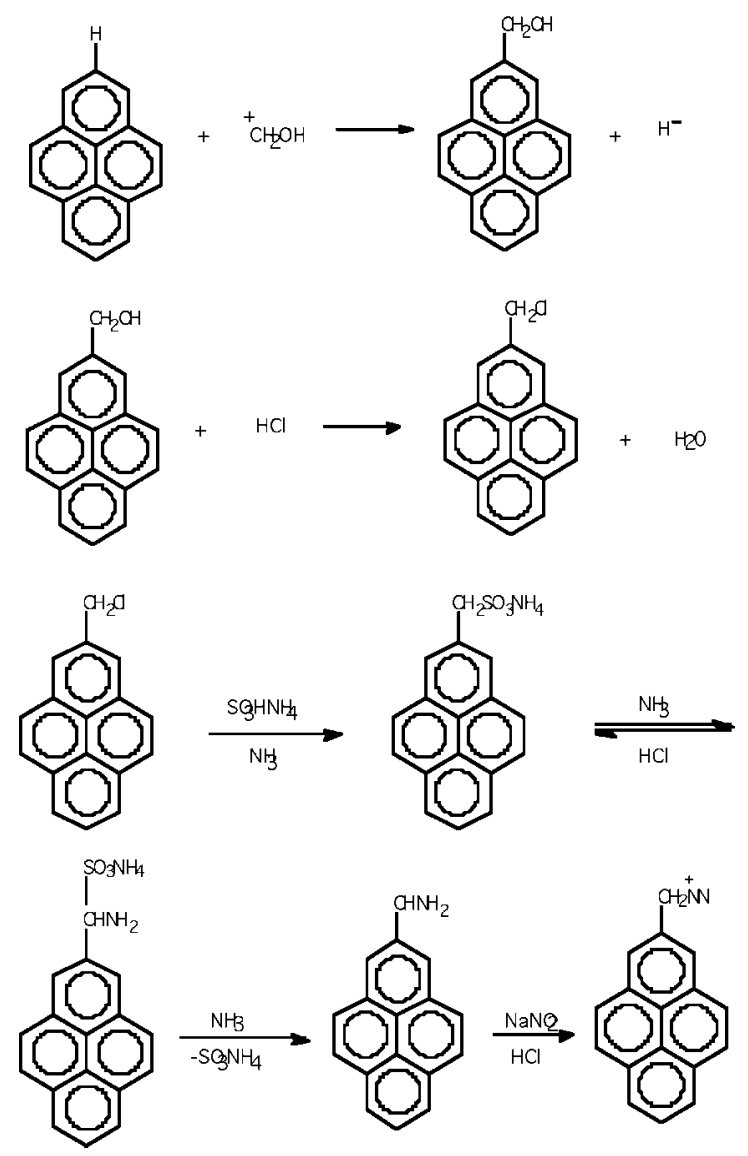

Figure 1

Synthesis pathway of 1- Pyrenyldiazomethane (PDAM).

\section{Derivatization of DSP toxins with PDAM}

The preparation of PDAM derivatives of toxins and standards were made using a $0.1 \%$ solution of PDAM in ethyl acetate in as described by Marr et al., 1994. Aliquots of $10 \mu \mathrm{l}$ of mussel or dinoflagellates extracts, DSP toxin standards and standard solution of Deoxycholic acid (DOCA, MW $=392.6 \mathrm{~g} / \mathrm{mol}$ ) were mixed with $100 \mu \mathrm{l}$ of PDAM solution and allowed to react for 90 minutes at room temperature. The mixture was subjected to a $\mathrm{C}_{18}$ SEP PAK cartridge (250 mg, Waters Assoc., Milford, MA, USA) and previously washed with $10 \mathrm{ml}$ methanol/water 1:1 (v/v). The cartridge was washed with $5 \mathrm{ml}$ of methanol/water $7: 3(\mathrm{v} /$ 
v) and then the toxin derivatives were eluted with $5 \mathrm{ml}$ of pure methanol. The toxin derivatives were evaporated to dryness, dissolved in $100 \mu$ l of ethyl acetate, and then 10 or $20 \mu \mathrm{l}$ were analyzed by HPLC. Figure 2 shows the reaction pathway of PDAM with DSP toxins.

\section{Derivatization of DSP toxins with ADAM}

The HPLC analysis of the ADAM derivatives of standards and DSP toxins samples were carried out as described by Uribe et al., 2001.
Briefly, the solid mussel, dinoflagellate extract residues, or DSP toxin standards were treated with a freshly-prepared solution of $0.1 \%$ ADAM (in $100 \mu \mathrm{l}$ of acetone and $400 \mu \mathrm{l}$ of methanol) (Lee et al., 1987). After one hour at $25{ }^{\circ} \mathrm{C}$ in darkness, the sample was evaporated to dryness and the residue was diluted in $200 \mu \mathrm{l} \mathrm{CH}_{2} \mathrm{Cl}_{2} /$ hexane, $1: 1(\mathrm{v} / \mathrm{v})$ and transferred into a $500 \mathrm{mg}$ Silica gel SEP PAK cartridge. The system was washed successively with $5 \mathrm{ml}$ of $\mathrm{CH}_{2} \mathrm{Cl}_{2} /$ hexane, 1:1 (v/v) and $5 \mathrm{ml} \mathrm{CH}_{2} \mathrm{Cl}_{2}$, and finally eluted with $5 \mathrm{ml}$ of $\mathrm{CH}_{2} \mathrm{Cl}_{2} /$ methanol, 1:1 (v/v). The last fraction was evaporated to dryness, dissolved

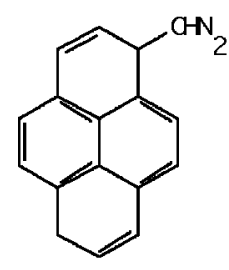

PDAM

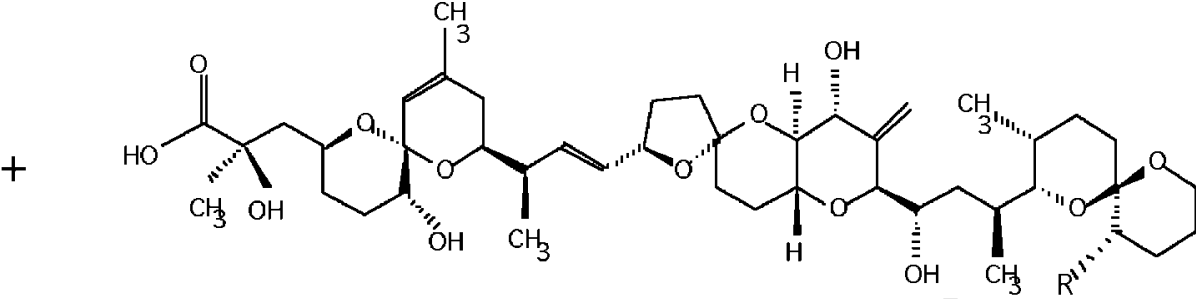
$\mathrm{R}$

Okadaic acid Dinophysistoxiß

Dark

Room temperature 90 minutes

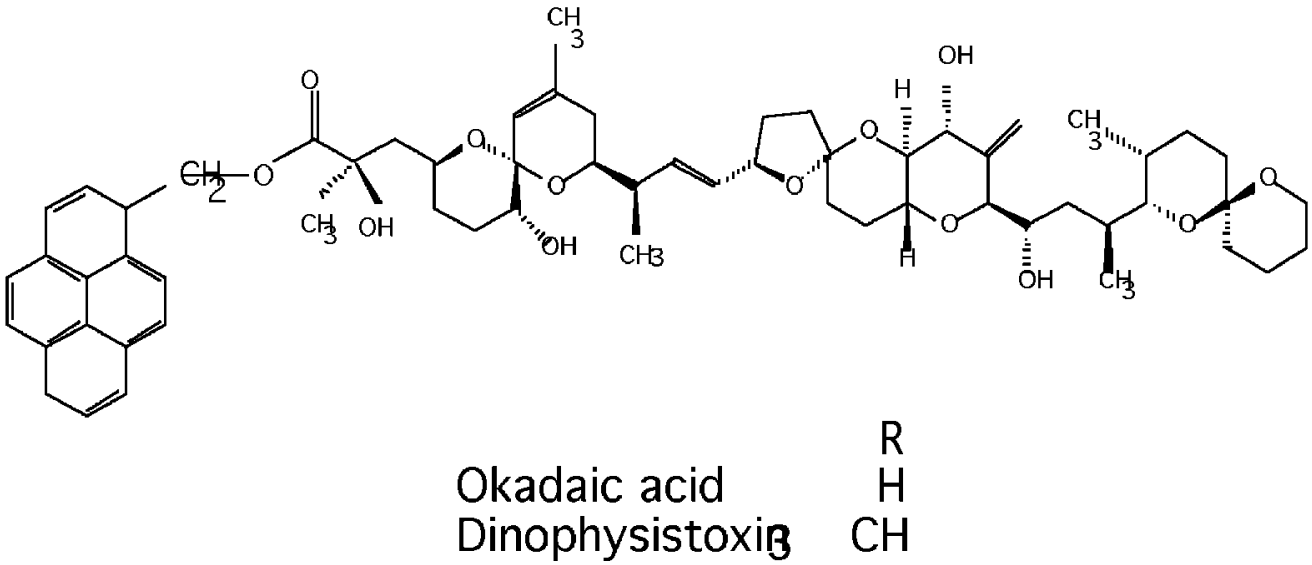

\section{Figure 2}

Reaction path of PDAM with DPS toxins. 
in $100 \mu \mathrm{l}$ methanol, and 10 or $20 \mu \mathrm{l}$ were injected and analyzed by HPLC-FLD.

\section{Chemical Analysis: HPLC-FLD method.}

HPLC chemical analysis was performed on a Shimadzu Liquid Chromatograph System equipped with a pump (Shimadzu LC-6A), a rheodyne injector (7725i Rheodyne. Cotati, CA, USA) and an on-line fluorescence detector (Shimadzu RF-535). Ten $\mu$ l of toxin derivatives were injected on a reversed phase column Supelcosil LC-18 (5 $\mu \mathrm{m} ; 25 \mathrm{~cm}$ x 4 $\mathrm{mm}$ ) (Supelco, Bellefonte, PA. USA). An isocratically mobile phase of $\mathrm{CH}_{3} \mathrm{CN} / \mathrm{CH}_{3} \mathrm{OH} /$ $\mathrm{H}_{2} \mathrm{O} 8: 1: 1(\mathrm{v} / \mathrm{v})$ with a flow rate of $1 \mathrm{ml} / \mathrm{min}$ was run at room temperature. The excitation and emission wavelengths were set at 365 and $415 \mathrm{~nm}$ respectively. Peaks in the resulting chromatograms were identified by comparison with the retention times of toxin analytical standards. This method correspond to a High Performance Liquid Chromatography with on line fluorescent detection (HPLC-FLD) and with precolumn derivatization.

\section{HPLC-MASS analysis}

HPLC-MS spectrometry was performed using a Hewlett Packard Model 1050 series liquid chromatograph coupled to a VG PLATFORM mass spectrophotometer (FISONS Instruments) equipped with an atmospheric pressure chemical ionization (APcI) device. The liquid chromatography flow was introduced into the interface without any splitting. High purity $99 \%$ nitrogen was used as the nebulizing gas. Separation of the sample was achieved on a C-18 column (Supelcosil $5 \mu \mathrm{m}$, ODS 4,6 x $150 \mathrm{~mm}$. SUPELCO), at room temperature and in isocratic conditions. The mobile phase was $90 \%$ aqueous acetonitrile at a flow rate of $0.2 \mathrm{ml} / \mathrm{min}$. A potential of 3.2 $\mathrm{kV}$ was applied at the corona and voltage of 30 Volts in the cones were used. The source temperature was set at $150{ }^{\circ} \mathrm{C}$ and the probe temperature was set at $350{ }^{\circ} \mathrm{C}$. The negative ion mode was used with a full scan between 100 to $900 \mathrm{~m} / z$. Mass calibration of the instrument was carefully checked.

\section{RESULTS AND DISCUSSION}

Synthesis, purity, stability and reaction of PDAM with carboxilic acid

The pathway selected for the synthesis of PDAM starting from pyrenylchloromethane was chosen due to the simple way of modifying the chloremethyl radical to aminomethyl by treatment with ammonia. First, in the position of the methyl group, a molecule of bisulphite is fixed and then the bisulphitic derivative reacts immediately with the ammonia, giving rise to the formation of pyrenylaminomethane, so this amino group is transformed into a diazo group by the reaction of the pyrenylaminomethane with the nitrous acid in presence of the hidrochloric acid at $0-4{ }^{\circ} \mathrm{C}$ (ice-water mixture). The outcome of this final reaction is diazonium salt with a typical brick red color (Fig. 1). The PDAM structure and purity were confirmed by mass spectrometry as illustrated in Figure 3A. The re-crystallized chromophore was analyzed by mass chromatography, giving only one sign of molecular ion of 216 $\mathrm{m} / \mathrm{z}$, which corresponds to the molecular ion form of pyrenyldiazomethane. Furthermore, the fragmented ion naphtalenbenzomethane also appeared at $179 \mathrm{~m} / \mathrm{z}$, produced by the cleavage of PDAM, confirming the structure of the PDAM synthesized (Fig. 3A).

The PDAM was found to react readily with carboxilic acids at room temperature without catalysts in methanol or ethyl acetate following the path reaction shows in Figure 2. The deoxycholic acid (DOCA), an inexpensive, low molecular weight organic acid that is stable at room temperature, was used as the internal standard of the HPLCFLD run, as well as a marker of functional derivatization reaction with both fluorescent chromophores (PDAM and ADAM). Figure 3B shows the excitation and emission fluorescence spectras of purified PDAM ester of DOCA in ethyl acetate. The excitation maximum was at $342 \mathrm{~nm}$ and the emission maximal at 375 and $395 \mathrm{~nm}$. The fluorescence intensity of the DOCA ester derive from PDAM was two times stronger than that from ADAM. 

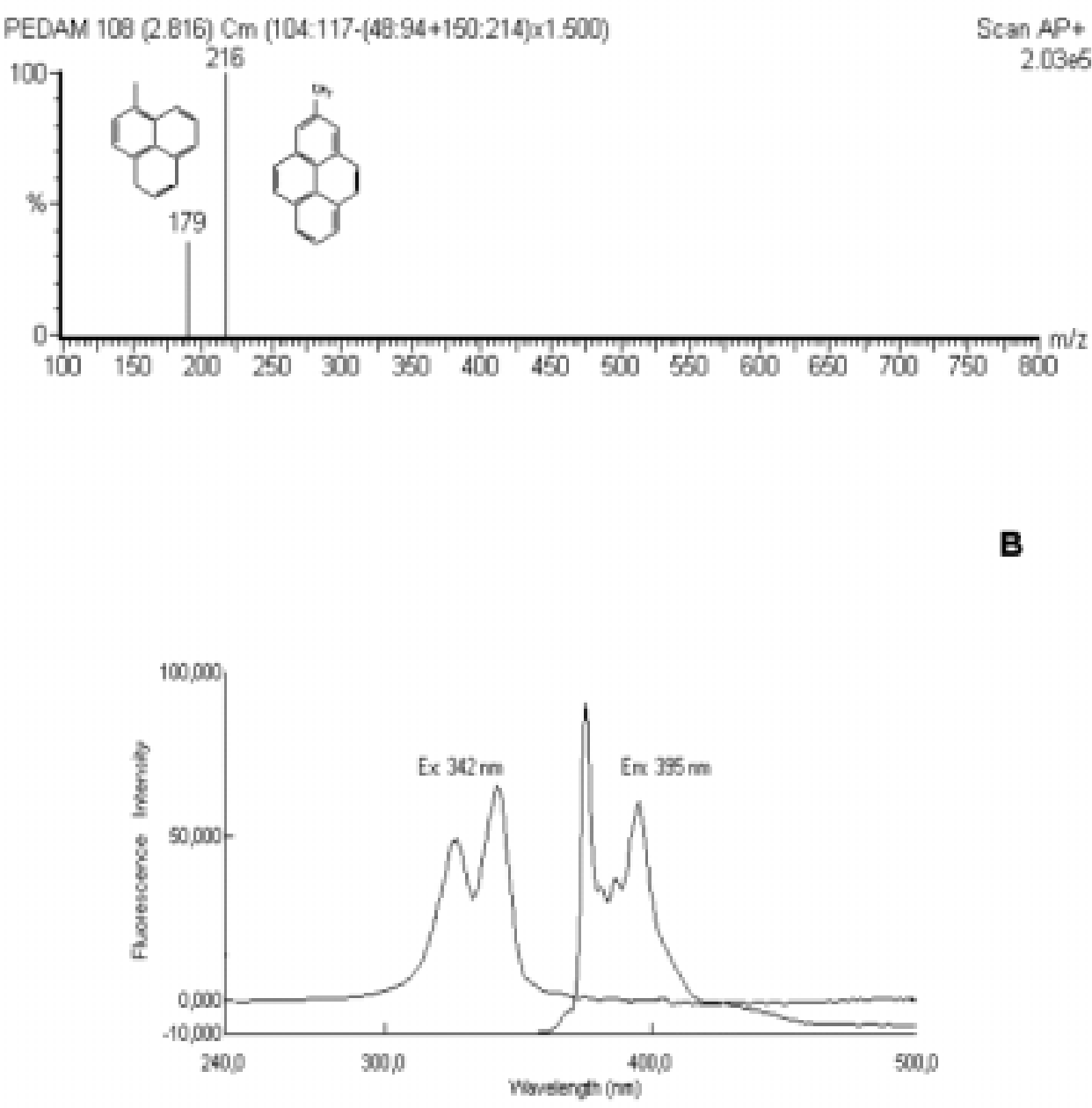

Figure 3

A. Mass spectra of purified PDAM. The structural formula indicates the proposed structure of PDAM and naphtalenbenzomethane. B. Fluorescence spectra of isolated DOCA-PDAM ester in ethyl acetate at room temperature.

Between the two solvents, ethyl acetate was found to be the best solvent not only for the estherification reaction, but mainly for the storage of the reagent (DOCA ester). The yield of the DOCA ester reached its maximum in 90 minutes, while the DSP toxins ester with ADAM reached its maximum in 60 minutes (Lee et al., 1987). The DOCA ester derivatized with PDAM proves to be very stable at room temperature, and a little better in an icewater mixture, when it was suspended in methanol or ethyl acetate after the derivatization reaction, as is shown in Figure 4A. Also, DOCA and DSP toxins derivatized with PDAM and maintained in ethyl acetate at $-20^{\circ} \mathrm{C}$, showed a remarkable stability (months) as shown in Figure 4B. It is important to mention that with respect to the stability of DSP toxins and DOCA derivatized with PDAM, that the esters were not only steady during the five months in which the experiments were done, but the DOCA ester was also stable to the freeze/ thaw procedures performed each month in order to measure the stored ester. 

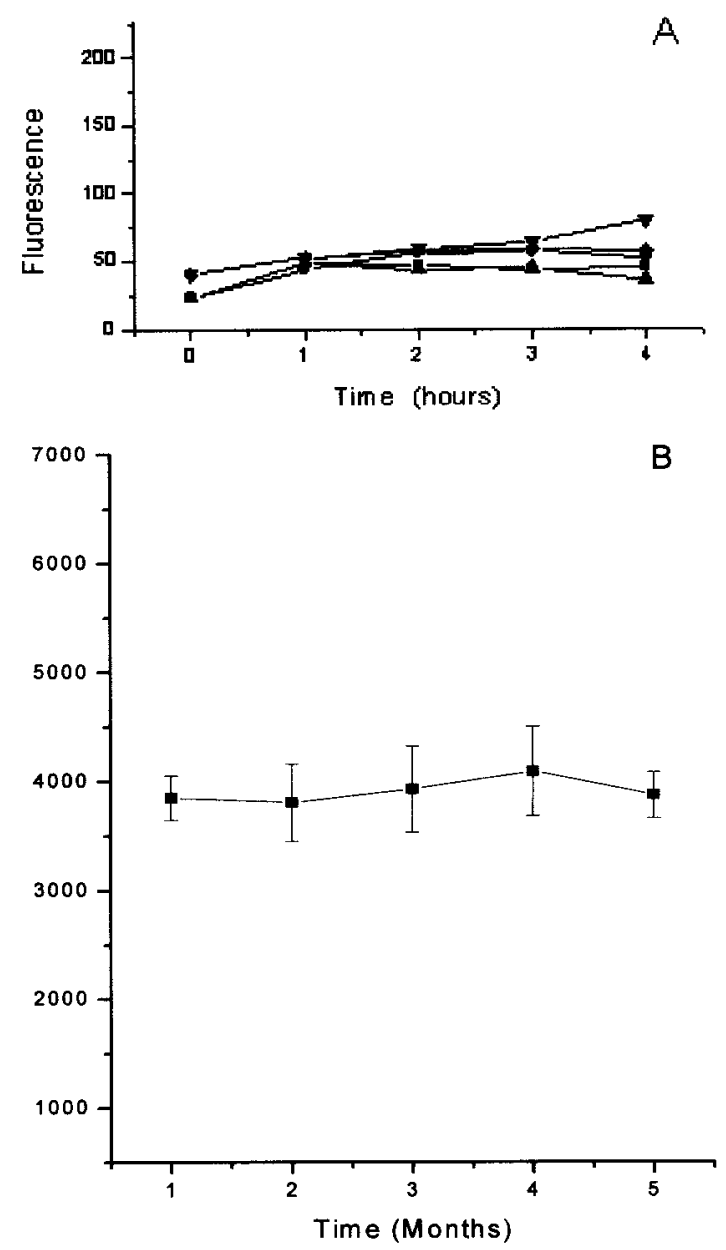

Figure 4

A. Stability of DOCA-PDAM ester under various conditions: Filled triangles, methanol at $-20{ }^{\circ} \mathrm{C}$. Filled squares, methanol $-4{ }^{\circ} \mathrm{C}$. Filled circles, methanol at room temperature. Filled inverted triangles, ethyl acetate at $0-4^{\circ} \mathrm{C}$. B. Stability of DOCA-PDAM ester stored at $-20^{\circ} \mathrm{C}$.

Once the chromophore was obtained, the ideal conditions of ester formation reaction were selected. In these studies, DOCA was assayed as the internal standard, rather than the DSP toxins. The best conditions of the derivatization reaction were in the resence of the solvent ethyl acetate at room temperature and then maintained at $0-4{ }^{\circ} \mathrm{C}$ during the time consumed in the analysis by HPLC-FLD. Under these conditions, a constant reading in time was obtained (Fig. 4A). When methanol was used as solvent, it gave a similar resolution, but at room temperature it presented a decay in the fluorescent signal (around 15\%) during the 4 hours tested. PDAM derivatization with DOCA is stable up to 5 months when frozen at $-20^{\circ} \mathrm{C}$ (Fig. 4B).

In order to compare the capacity of both chromophores as fluorescent labeling reagents, DOCA was derivatized with PDAM and ADAM at different concentrations of both labeling reagents (from 0.0 to 25.0 nanograms $/ \mathrm{ml}$ ). Figure 5 shows that both chromophores behave similarly at the same known concentrations tested, the quantitation shows an excellent linearity with a correlation coefficient of 0.958. The amount of both chromophores were represented by the peak areas of the DOCA ester.

Detection method and analysis of DSP toxins in mussel and dinoflagellate samples

Standard okadaic acid (OA), the first DSP toxin described in the literature (Yasumoto and Murata, 1993), was derivatized with PDAM. Figure 6A shows the liquid chromatography

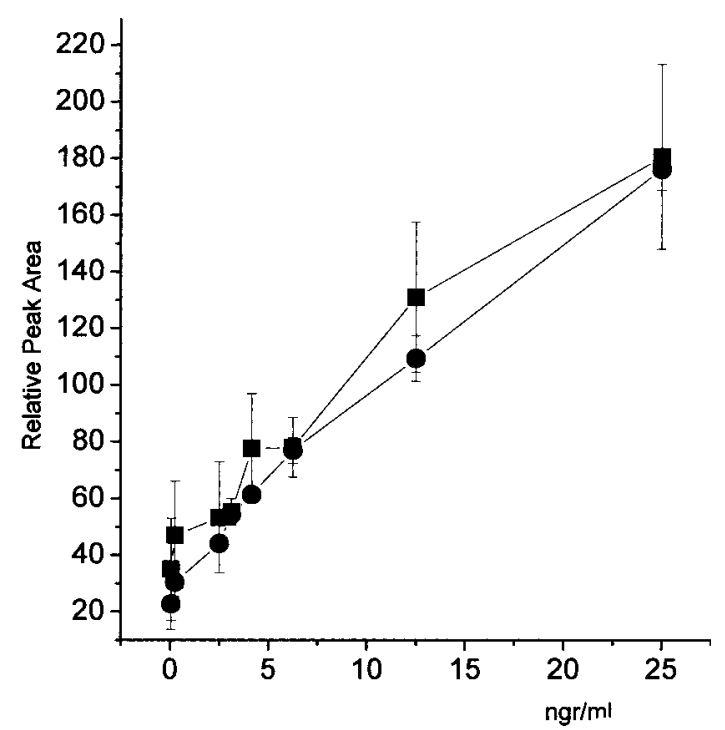

Figure 5

Comparison of the fluorescence quantitative results using as labeling reagents PDAM and ADAM at different concentrations (0.0 to 25.0 nanograms $/ \mathrm{ml}$ ). The amount of both chromophores were represented by the peak areas of the DOCA ester. Filled squares, ADAM and filled circles, PDAM. 


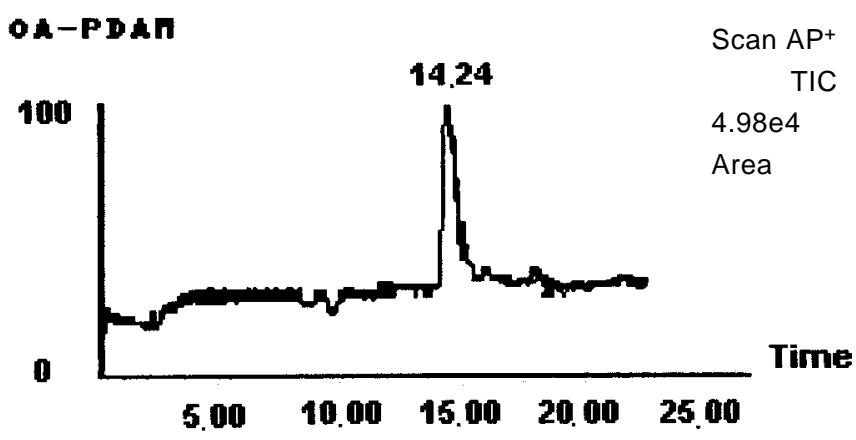

B
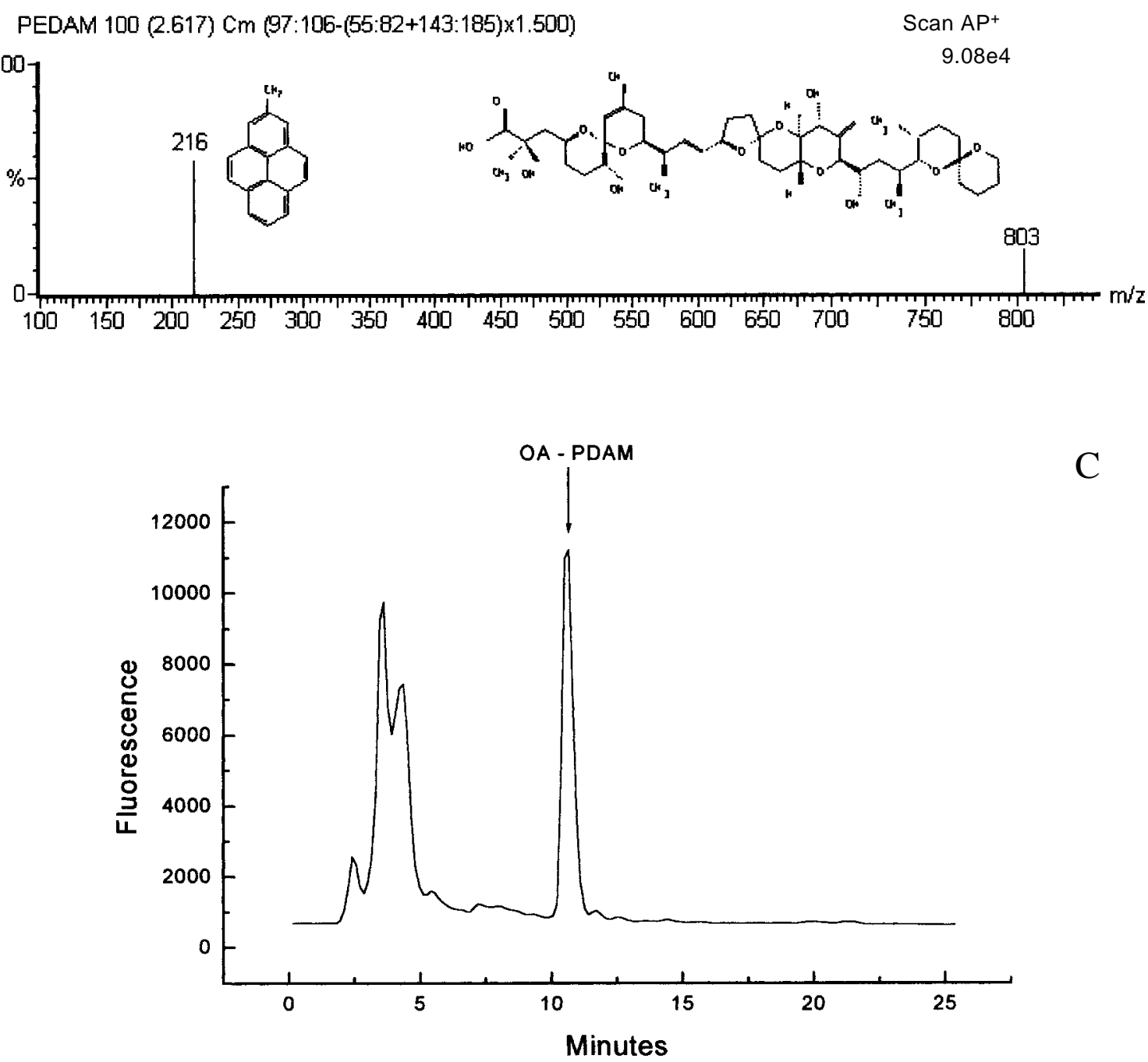

Figure 6

A. Mass chromatogram of $\mathrm{MH}^{+}$ions of OA-PDAM ester. B. Positive ion mass spectra of the reaction product of okadaic acid with PDAM. The structural formulas indicates the proposed structure of OA and PDAM. C. Chromatogram obtained from HPLC-FLD analysis of OA-PDAM standard. 
mass chromatogram of the separation of OAPDAM ester with a retention time of 14:24 minutes. This figure also shows that OAPDAM was the only compound purified in the total run of 25 minutes.

The mass spectra of the reaction product of OA with PDAM is shown in Figure 6B. The mass spectra obtained from full-scan mass chromatogram display two molecular ion peaks at $803 \mathrm{~m} / \mathrm{z}$ and $216 \mathrm{~m} / \mathrm{z}$ corresponding to $\mathrm{OA}$ and PDAM respectively. The cleavage of the ester gave two fragments which correlate with both initial components. This fragmentation is due to the cone voltage energy employed in the mass analysis. The chromatographic run of OA-PDAM ester detected by HPLC-FLD is shown in Figure 6C. Here, a single clear peak with a retention time at 10:26 minutes shows that this ester is the only fluorescent signal detected. The PDAM reagent also appeared at the beginning of the run and exceeded the derivatization reaction (Fig. 6C). This chromatogram corresponds to online fluorescent detection of a pre-column derivatization procedure and the one obtained in the regular method developed in this paper for detection and quantitation of DSP toxins as routine analysis.

Table I shows the variation coefficients of the esters derivatized with ADAM and PDAM respectively and measured by HPLC-FLD during five months of storage at $-20^{\circ} \mathrm{C}$. Both types of ester were frozen and thawed each month in order to perform the HPLC-FLD analysis. This data confirms that PDAM behave similarly to ADAM when were derivatized with DOCA or with DSP toxins. The PDAM ester with DOCA and the DSP toxins can be stored at least for a year and used as standards of HPLCFLD run for DSP toxins analysis.

Using the derivatization conditions found above for DOCA and standard DSP toxins (OA and DTX-1), the analysis of mussel and dinoflagellates extracts was performed. Figure 7A shows the HPLCFLD chromatogram of mussel extract from M. chilensis collected in the XI Region after the summer 2000. The chromatographic run shows a unique peak with a retention time of 16:50 minutes that corresponds to DTX-1. The presence of this DSP toxin is not unusual, as of nearly all the samples measured by our laboratory to date, DTX-1 is the major or only DSP toxin detected (Uribe et al., 2001; Lagos, 2002). This analysis correlates well with the the findings of Zhao et al., 1993, using the same HPLC-FLD procedure, but with ADAM as fluorescent labeling reagent. They also found DTX-1 as the major DSP toxins in Chilean mussel samples (Zhao et al., 1993). The total amount of DTX-1 determined in the mussel sample analyzed was $300 \mathrm{ng}$ of DSP toxin / grams of digestive glands, this amount is above the international safe limit, $200 \mathrm{ng}$ of DSP toxins / grams of digestive glands.

To date, only two genera of dinoflagellates have been described as DSP toxins producers, Dinophysis spp. and Prorocentrum spp. Since not all the Dinophysis species have been cultivated

TABLE I

Comparison of the fluorescence measurements of the DOCA and DSP toxin esters stored at $-20{ }^{\circ} \mathrm{C}$ for five months

\begin{tabular}{llcc}
\hline Esters & Amount & $\mathrm{N}$ & $\mathrm{CV}$ \\
\hline DOCA - ADAM & $2 \mathrm{ng} / \mathrm{ult}$ & 4 & $9.38 \pm 0.022$ \\
DOCA - PDAM & $2 \mathrm{ng} / \mathrm{ult}$ & 4 & $10.26 \pm 0.017$ \\
OA - ADAM & $2 \mathrm{ng} / \mathrm{ult}$ & 4 & $12.18 \pm 0.016$ \\
OA - PDAM & $2 \mathrm{ng} / \mathrm{ult}$ & 4 & $12.60 \pm 0.112$ \\
DTX1 - ADAM & $2 \mathrm{ng} / \mathrm{ult}$ & 4 & $11.62 \pm 0.029$ \\
DTX1 - PDAM & $2 \mathrm{ng} / \mathrm{ult}$ & 4 & $13.11 \pm 0.050$ \\
\hline
\end{tabular}



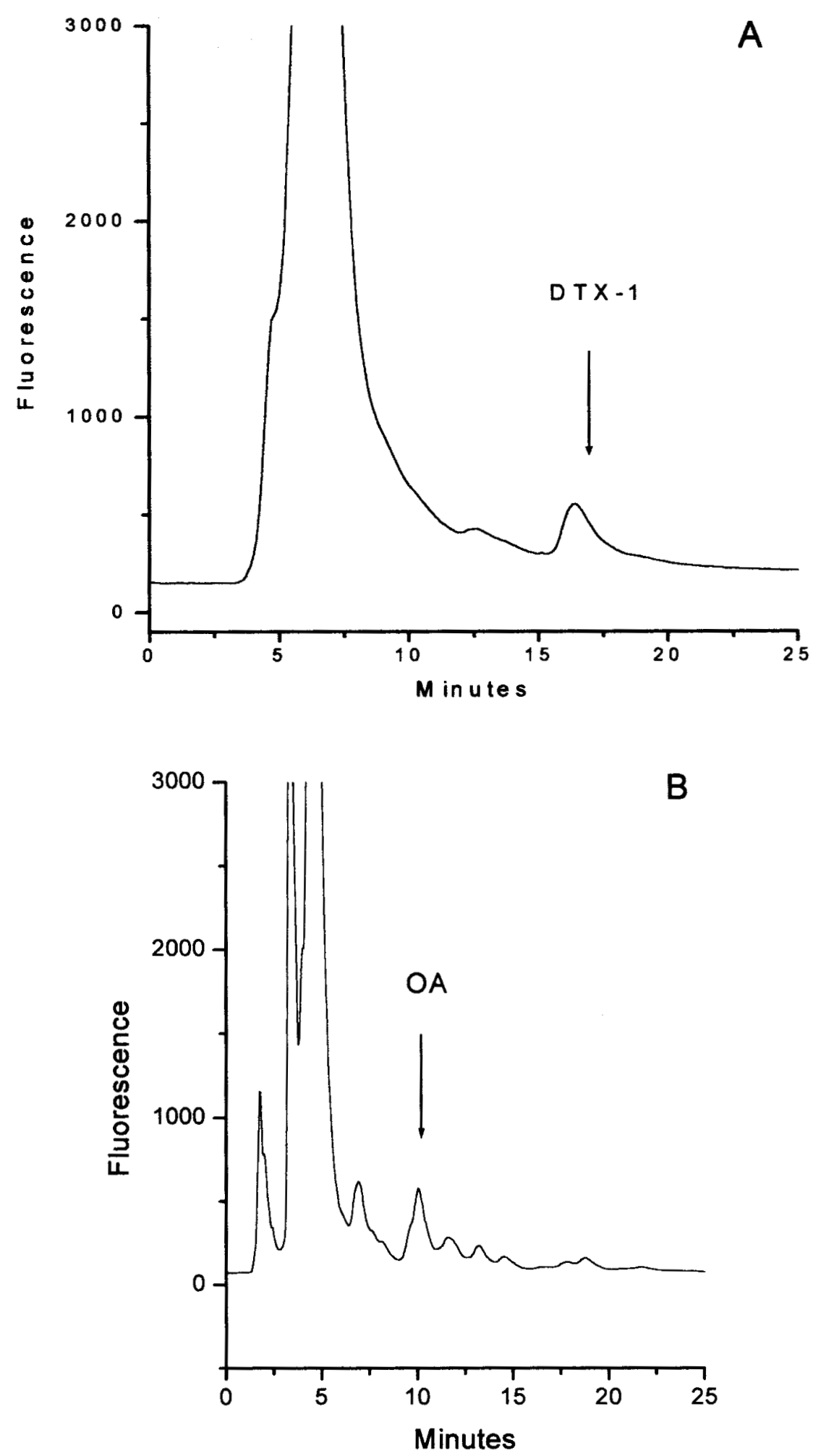

Figure 7

A. Chromatogram obtained from HPLC-FLD analysis of an extract of mussel collected in the XI Region. B. Chromatogram obtained from HPLC-FLD analysis of an extract of the dinoflagellate $P$. lima isolated in Portugal and maintained under laboratory controlled conditions. 
under laboratory conditions, Prorocentrum lima was used in this study, as it was cultivated and maintained under laboratory controlled conditions as a dinoflagellate sample. The fluorometric HPLC chromatogram of the $P$. lima extract is shown in Figure 7B; a peak with a retention time of 10:22 minutes is clearly detected and corresponds to the OA standard (Fig. 6C).

The routine procedures of extraction and HPLC-FLD analysis described in this paper were performed in both of the HPLC-FLD analyses shown above. PDAM was used as the fluorescent labeling reagent in both cases. The above results suggest that PDAM is suitable for high performance liquid chromatographic determination with fluorescent detection of DSP toxins, as it gives an intensely fluorescent ester with DOCA and DSP toxins.

Diarrhetic shellfish poisoning produces a severe intoxication in humans, with symptoms of diarrhea, nausea, and stomach pain. On average they recover within three days with no apparent serious after-effects.

Diarrheagenicity of OA and the other DSP toxins was first demonstrated by Hamano et al., 1986. In the same year, Tero et al., 1986 showed that DTX-1 caused severe injuries on the intestinal mucous and Suganuma et al., 1988, provided evidence that classifies these compounds as potent tumor promoters. Since Chile's procedure is to use only a qualitative, low sensitive and non-specific mouse bioassay performed as a referential assay of DSP toxin detection, attention should be paid to the continuous uptake of subacute levels of DSP toxins through seafood in order to provide safe health care. Economic damage to the shellfish industry is also severe, as harvesting shellfish is banned during the contamination period, which may last half a year or more. The DSP illness has a worldwide distribution but is most prevalent in Europe, Japan and Chile, where shellfish culture and salmon aquaculture are extensively carried out. The accurate measurement of DSP toxins is a topic of growing concern worldwide, and should be in Chile as well, as its three southernmost regions have had endemic DSP contamination since 1970 (Avaria, 1979; Lembeye et al., 1993; Zhao et al., 1993; Uribe, et al., 2001).

\section{ACKNOWLEDGEMENTS}

This study was supported by FONDECYT 1020090 and DID, Universidad de Chile, CSMAR 02/5-2.

\section{REFERENCES}

ANDERSON DM (1989) Toxic algal blooms and red tides: a global perspective. In: OKAICHI T,

ANDERSON DM, NEMOTO T (eds) Red Tides: Biology, Environmental Science and Toxicology. New York: Elsevier. pp: 11-16

AVARIA S(1979) Red tides off the coast of Chile. In TAYLOR DL, SELIGER HH (eds) Toxic dinoflagellate blooms. Amsterdam: Elseiver. pp 215-220

COMPAGNON D, LEMBEYE G, MARCOS N, RUIZTAGLE N, LAGOS N (1998) Accumulation of paralytic shellfish poisoning toxins in the bivalve Aulacomya ater and two carnivorous gastropods Conchalepas conchalepas and Argobuccinum ranelliformes during an Alexandrium catenella bloom in southern Chile. J Shellfish Res 17: 67-73

FALCONER IR(1996) Potencial impact on human health of toxic cyanobacteria. Phycologia 36: 6-11

HALLEGRAEFF GM(1993) A Review of harmful algal blooms and their apparent global increase. Phycologia 32: 79-99

LAGOS N (1998) Microalgal blooms: A global issue with negative impact in Chile. Biol Res 31: 375-386

LAGOS N (2002) Principales toxinas de origen fitoplanctónico: Identificación y cuantificación mediante cromatografía líquida de alta resolución (HPLC). IN: SAR EA, FERRARIO ME, REGUERA B (eds) Floraciones Algales Nocivas en el Cono-Sur Americano. Instituto Español de Oceanografía

LEE JS, YANAGI T, KENMA R, YASUMOTO T (1987) Fluorometric determination of diarrhetic shellfish toxins by high-performance liquid chromatography. Agric Biol Chem 51: 877-81

LAGOS N, COMPAGNON D, SEGUEL M, OSHIMA Y (1996) Paralytic shellfish toxin composition: a quantitative analysis in Chilean mussels and dinoflagellate. Harmful and Toxic Algal Blooms. UNESCO Intergovernmental Oceanographic Commission. pp: 121-124

LEMBEYE G, GUZMÁN L, CAMPODINICO I (1975) Estudios sobre un florecimiento tóxico causado por Gonyaulax catenella en Magallanes. III. Fitoplancton asociado. An Inst Patagonia. Punta Arenas (Chile) 4:197-208

LEMBEYE G, YASUMOTO T, ZHAO J, FERNÁNDEZ R (1993) DSP outbreak in Chilean fiords. In: SAMYDA TJ, SHIMIZU Y (eds) Toxic Phytoplankton blooms in the sea. New York: Elsevier. pp: 525-529

MARR JC, MCDOWELL LM, QUILLIAM MA (1994) Investigation of derivatization reagents for the analysis of diarrhetic shellfish poisoning toxins by liquid chromatography with fluorescence detection. Natural Toxins 2: 302-311

MUÑOZ P, AVARIA S, SIEVERS H, PRADO R (1992) Presencia de dinoflagelados tóxicos del género Dinophysis en el seno de Aysén, Chile. Revista Biología Marina (Valparaíso) 27: 187-212

NIMURA N, KINOSHITA T, YOSHIDA T, UETAKE A; NAKI C (1988) 1- Pyrenyldiazomethane as a fluorescent labeling reagent for the liquid chromatographic determination of carboxylic acids. Anal Chem 60: 2067-2070 
PROENCA LAO, RORIG L, SILVA M, GUIMARAES S, LAGOS N (1997) PSP outbreak in Brazil. Harmful algae news. Paris: Intergovernmental Oceanographic Commiccion (IOC), UNESCO, $\mathrm{N}^{\circ} 16$. pp: 1-3

RIVAS M, GARCÍA C, LIBERONA JL, LAGOS N (2000) Biochemical characterization and inhibitory effects of dinophysistoxin-1, okadaic acid and microcystine L-R on protein phosphatase $2 \mathrm{~A}$ purified from the mussel Mytilus chilensis. Biol Res, 33: 197 - 206

SMAYDAT(1992) Global epidemic of noxious phytoplancton blooms and food chain consequences in large ecosystems. In: KLMA S, GOLD BD (eds) Food chain yields, models and management of large ecosystem. Boulder: Westview. pp: 275-307

SUGANUMA M, FUJIKI H, SUGURI H, YOSHIZAWA S, HIROTA M, NAKAYASU M, OJIKA M, WAKAMATSU K, YAMADA K, SUGIMURA T (1988) Okadaic acid: a new non-12- $O$-tetradecanoyl phorbol acetate type tumor promoter. Proceedings Nat Acad Sci USA 85: 1768-1773

URIBE JC (1993) PSP outbreak in Chile. In: Sixth international conference on toxic marine phytoplancton. Nantes, France. 18-22 October, Abstracts. pp: 210
URIBE JC, GARCÍA C, RIVAS M, LAGOS N (2001) First Report Diarrhetic Shellfish Toxins in Magellanic Fiords, Southern Chile. J Shellfish Res 20: 69-74

WHITE AW (1988) Blooms of toxic algae worldwide: Their effects on fish farming and shellfish resource. Proc Intl Conf Impact of Toxic Algae Mariculture. Aqua-Nor 187 Exhibition, Trondhein, Norway, 13-18 August 1987. pp: 9-14

YASUMOTO T, OSHIMA Y, YAMAGUCHI M (1978) Bul Jpn So Sci Fish 44 : 1249-1255

YASUMOTO T, MURATA M (1993) Marine Toxins. Chem Rev 93: 1897-1909

YASUMOTO T, FUKUI M, SASAKI K (1995). Determination of marine toxin in foods. J AOAC Intl 78: 574582

ZHAO J, LEMBEYE G, CENCI G, WALL B, YASUMOTO T (1993) Determination of okadaic acid and dinophysistoxin-1 in mussels from Chile, Italy and Ireland. In: SMAYDA J and SHIMIZU Y (eds) Toxic Phytoplankton Blooms in the Sea. Amsterdam, Netherlands: Elsevier Science Publishers. pp. 587-592 